\title{
Failure of glucagon suppression contributes to postprandial hyperglycaemia in IDDM
}

\author{
S. Dinneen, A. Alzaid, D. Turk, R. Rizza \\ Endocrine Research Unit, Department of Medicine, Mayo Clinic, Rochester, Minnesota, USA
}

\begin{abstract}
Summary Carbohydrate ingestion results in a fall in glucagon concentration in non-diabetic but not in diabetic individuals. To determine if, and the mechanism by which, lack of postprandial suppression of glucagon contributes to hyperglycaemia, nine subjects with insulin-dependent diabetes mellitus (IDDM) ingested $50 \mathrm{~g}$ of glucose containing both [2$\left.{ }^{3} \mathrm{H}\right]$ glucose and $\left[6^{3} \mathrm{H}\right]$ glucose on two occasions. [6$\left.{ }^{14} \mathrm{C}\right]$ glucose, insulin and low-dose somatostatin were infused intravenously at the same rates on both occasions. A basal glucagon infusion was started either at the same time ("constant glucagon") or $2 \mathrm{~h}$ following ("suppressed glucagon") glucose ingestion. This resulted in lower $(p<0.001)$ glucagon concentrations during the first $2 \mathrm{~h}$ of the suppressed than during the constant glucagon study days $(63 \pm 1$ vs $108 \pm 2 \mathrm{pg} /$ $\mathrm{ml}$ ). Lack of suppression of glucagon led to higher $(p<0.01)$ postprandial glucose concentrations $(10.3 \pm 0.9$ vs $8.1 \pm 0.7 \mathrm{mmol} / \mathrm{l})$ and a greater
\end{abstract}

$(p<0.02)$ integrated glycaemic response. The excessive rise in glucose was due to higher $(p<0.02)$ rates of postprandial hepatic glucose release during the constant than during the suppressed glucagon study days, whether measured using either $\left[6-{ }^{3} \mathrm{H}\right]$ glucose $\left(2.6 \pm 0.2\right.$ vs $2.0 \pm 0.2 \mathrm{mmol} \cdot \mathrm{kg}^{-1}$ per $\left.6 \mathrm{~h}\right)$ or $\left[2-{ }^{3} \mathrm{H}\right]$ glucose $\left(3.0 \pm 0.3\right.$ vs $2.4 \pm 0.2 \mathrm{mmol} \cdot \mathrm{kg}^{-1}$ per $\left.6 \mathrm{~h}\right)$ as the meal tracer. Glucose disappearance, initial splanchnic glucose clearance and hepatic glucose cycling did not differ on the two occasions. Thus, the present studies demonstrate that lack of postprandial suppression of glucagon, by increasing hepatic glucose release, contributes to hyperglycaemia in subjects with IDDM. [Diabetologia (1995) 38: 337343]

Key words Hepatic glucose release, hepatic glucose cycling, glucose/glucose 6-phosphate cycling, insulindependent diabetes mellitus.
Insulin-dependent diabetes mellitus (IDDM) is associated with both insulin deficiency and glucagon excess. This has led to the so-called bihormonal hypothesis of diabetes which postulates that abnormalities in secretion of both hormones contribute to carbohydrate intolerance $[1,2]$. Hyperglucagonaemia can increase glucose output by stimulating glycogenolysis, gluconeogenesis and/or glucose/glucose 6-phosphate cycling [3-5]. Glucagon can also antagonize insulin or glucose-induced stimulation of glycogen synthesis [6]. Each of these actions could potentially cause hypergly-

Received: 20 April 1994 and in revised form: 30 August 1994

Corresponding author: Dr. R. Rizza, Endocrine Research Unit, 5-164 West Joseph, Mayo Clinic, Rochester, MN 55905, USA Abbreviations: IDDM, Insulin-dependent diabetes mellitus. caemia, the former by increasing postprandial hepatic glucose release and the latter by decreasing initial splanchnic glucose extraction, thereby forcing peripheral tissues to dispose of increased amounts of glucose.

Despite these theoretical considerations, experimental data supporting a contribution of glucagon excess to postprandial hyperglycaemia are not compelling. Infusion of glucagon has been reported not to alter either intravenous or oral glucose tolerance in non-diabetic subjects [7-9]. While acute increases in glucagon can increase glucose [3-5], fasting glucagon concentrations in subjects with IDDM are only slightly higher than those present in non-diabetic subjects and increase minimally if at all following carbohydrate ingestion $[1,2,10,11]$. This pattern however is distinctly abnormal since glucagon concentrations 
in non-diabetic subjects decrease $20-30 \%$ immediately after glucose ingestion [12-14].

In view of the above, the primary question becomes whether or not lack of postprandial glucagon suppression exacerbates hyperglycaemia in individuals who cannot compensate by increasing their endogenous insulin secretion. To address this question we studied subjects with IDDM on two occasions; endogenous glucagon secretion was inhibited on both occasions by means of a somatostatin infusion. Glucagon was infused in a fashion that maintained calculated portal concentrations either constant or mimicked the pattern of postprandial suppression that is normally observed in non-diabetic individuals following a carbohydrate meal. Intravenous insulin was infused at rates that created only modest insulin deficiency. The test meal contained both $\left[6-{ }^{3} \mathrm{H}\right]$ glucose and $\left[2-{ }^{3} \mathrm{H}\right]$ glucose while $\left[6{ }^{14} \mathrm{C}\right]$ glucose was infused intravenously in order to determine whether the resultant hyperglycaemia (if observed) was due to decreased initial splanchnic glucose extraction, increased postprandial hepatic glucose release and/or hepatic glucose cycling.

\section{Subjects and methods}

Subjects. Following approval by the Mayo Institutional Review Board, nine volunteers with IDDM, who were otherwise in good health, gave their written informed consent to participate in this study. The group comprised three males and six females of mean age $32 \pm 3$ years and mean body mass index $24 \pm 1 \mathrm{~kg} / \mathrm{m}^{2}$. All patients were C-peptide deficient. Their mean duration of diabetes was 8 years (range 3-17 years) and their mean level of glycated haemoglobin on entry into the study was $11 \pm 1 \%$ (normal 4-7\%). Apart from two patients who were on hormone replacement therapy (one on thyroxine and one on conjugated oestrogen) none were taking any other medications.

Protocol. Volunteers were studied on two occasions in random order with at least 2 weeks' interval between studies. On each occasion volunteers were admitted to the Clinical Research Center at 17.00 hours having omitted their morning dose of long-acting insulin. Following admission, two intravenous cannulae were placed, one in each forearm. One cannula was used for overnight blood sampling while the other was connected to a multiport infusion set (Burron Medical Inc., Bethlehem, Pa., USA) and used for all study infusions. Between 17.00 and 18.00 hours a standard meal $(636 \mathrm{kcal} ; 48 \%$ carbohydrate, $32 \%$ fat, $19 \%$ protein) was ingested. Following this meal volunteers were fasted until the following morning. Coincident with the evening meal, an intravenous insulin infusion (1 IU per $10 \mathrm{ml}$ of albuminized saline) was initiated. The rate of the insulin infusion was varied using the algorithm of White et al. [15] in order to achieve and maintain euglycaemia throughout the night.

Between 06.30 and 06.50 hours the next morning the overnight sampling cannula was removed and replaced with a retrograde cannula in an ipsilateral hand vein. This hand was then placed in a heated $\left(55-60^{\circ} \mathrm{C}\right)$ plexiglass box to enable sampling of arterialized blood. At 07.00 hours a primed $(-12 \mu \mathrm{Ci})$, continuous $(\sim 0.12 \mu \mathrm{Ci} / \mathrm{min})$ intravenous infusion of $\left[6-{ }^{14} \mathrm{C}\right]$ glucose was commenced to enable measurement of glucose turnover rates. At 10.00 hours, having allowed sufficient time for isotopic equilibration, volunteers ingested a 50 -g glucose drink which was flavoured with a non-caloric flavoured powder (Kraft General Foods Inc., White Plains, N. Y., USA). The glucose drink contained approximately $100 \mu \mathrm{Ci}$ each of $\left[6-{ }^{3} \mathrm{H}\right]$ glucose and $\left[2{ }^{3} \mathrm{H}\right]$ glucose to enable measurement of the rate of appearance of ingested glucose $[13,16]$. In addition, volunteers drank $100 \mathrm{ml}$ of water containing $10 \mathrm{~g}$ of $\mathrm{D}$-xylose (a sugar which is absorbed but not metabolized) to provide an estimate of carbohydrate absorption.

The insulin infusion rate required to achieve euglycaemia prior to drink ingestion was continued throughout the postprandial period. The last adjustment of the infusion rate was made no earlier than $45 \mathrm{~min}$ prior to the meal. The fixed basal insulin infusion was supplemented by a second computer-driven insulin infusion that was started at the time of meal ingestion. As previously described [17], the computer program was designed to infuse insulin in a pattern which resulted in systemic insulin concentrations that mimicked those observed in nondiabetic volunteers following ingestion of the same amount of glucose. However, in order to render the diabetic volunteers modestly insulin-deficient during the postprandial period, the amount of insulin given during the postprandial infusion equaled only $75 \%$ of the non-diabetic profile [17].

On both study days, an infusion of somatostatin (7 ng . $\mathrm{kg}^{-1} \cdot \mathrm{min}^{-1}$ ) was commenced at the time of glucose ingestion and continued for $360 \mathrm{~min}$. Growth hormone was also infused at a rate of $3 \mathrm{ng} \cdot \mathrm{kg}^{-1} \cdot \mathrm{min}^{-1}$ to maintain constant basal concentrations. On one occasion (the constant study day) glucagon was infused at a rate of $0.65 \mathrm{ng} \cdot \mathrm{kg}^{-1} \cdot \mathrm{min}^{-1}$ from 0 to $360 \mathrm{~min}$. On the other occasion (the suppressed study day) glucagon was infused at the same rate but the infusion was started at $120 \mathrm{~min}$ after meal ingestion. Therefore, glucagon was allowed to fall from 0 to $120 \mathrm{~min}$. In one individual the glucagon infusion rate was $0.8 \mathrm{ng} \cdot \mathrm{kg}^{-1} \cdot \mathrm{min}^{-1}$ rather than $0.65 \mathrm{ng}$. $\mathrm{kg}^{-1} \cdot \mathrm{min}^{-1}$. Blood was sampled from the arterialized hand vein for determination of glucose-specific activity as well as glucose and hormone concentrations.

Analysis. Glucose was measured using a glucose oxidase method (Yellow Springs Instruments, Yellow Springs, Ohio, USA). Plasma insulin, C-peptide and glucagon were measured by radioimmunoassay as previously described $[13,14]$. Growth hormone was measured using a commercially available kit (ICN Biomedicals, Costa Mesa, Calif., USA) and D-xylose by a colorimetric assay [18]. $\left[6{ }^{-3} \mathrm{H}\right]$ glucose, $\left[2{ }^{3} \mathrm{H}\right]$ glucose and $\left[6-{ }^{14} \mathrm{C}\right]$ glucose (corrected for Cori cycle) specific activities were determined by radioenzymatic degradation as previously described $[13,16,19]$.

Calculations. Glucose turnover was calculated using Steele's non-steady-state equations [20]. The pool correction factor was assumed to be 0.65 and the volume of distribution of glucose $200 \mathrm{ml} / \mathrm{kg}$. Rates of glucose appearance and disappearance were calculated using $\left[{ }^{14}-{ }^{14} \mathrm{C}\right]$ glucose as the systemic tracer. In addition, $\left[6^{-14} \mathrm{C}\right]$ glucose was used to trace the appearance of the $\left[2-{ }^{3} \mathrm{H}\right]$ glucose and $\left[6-{ }^{3} \mathrm{H}\right]$ glucose contained in the meal $[13,16]$. Initial splanchnic glucose clearance was calculated by subtracting the integrated appearance of ingested glucose over a 6-h period from the total amount of glucose ingested $[13,16]$. Hepatic glucose release was calculated as the difference between total glucose appearance and the appearance of ingested glucose as previously described $[13,16]$. Since two meal tracers were employed this yielded two estimates of hepatic glucose release. As previously described, hepatic glucose cycling was calculated $[13,19]$ as the difference between the appearance of $\left[2{ }^{-3} \mathrm{H}\right]$ glucose (a tracer which is detritiated 


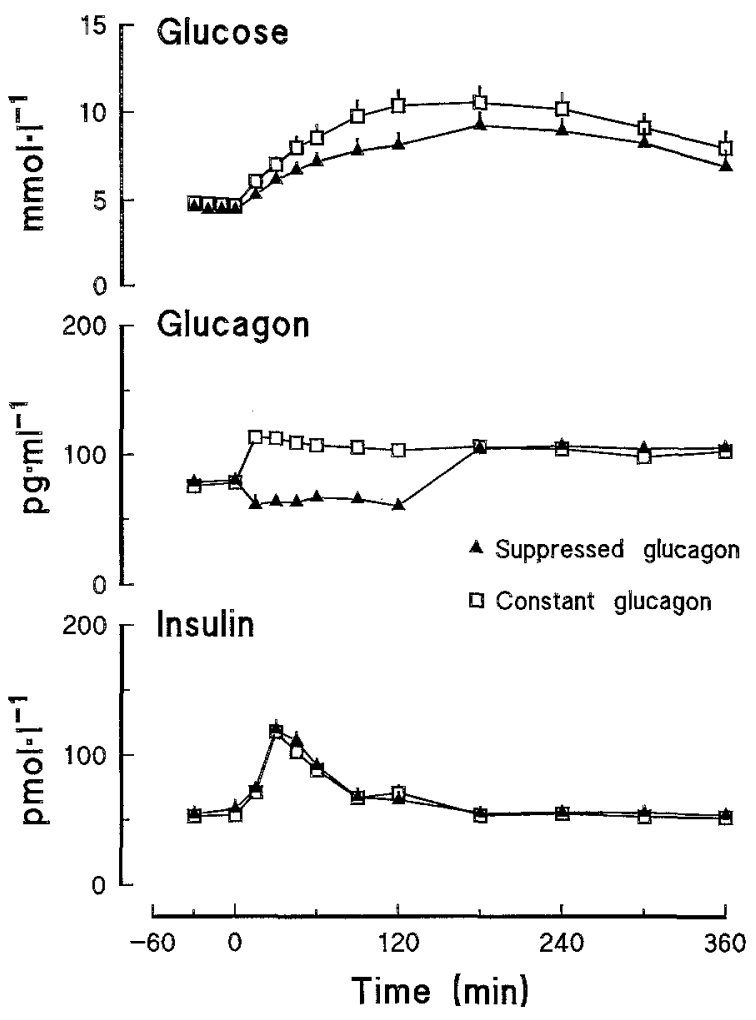

Fig. 1. Plasma glucose, glucagon and insulin concentrations observed when glucagon was continuously infused from 0 to $360 \mathrm{~min}$ (constant glucagon) or from 120 to $360 \mathrm{~min}$ (suppressed glucagon). At time zero $50 \mathrm{~g}$ glucose was ingested

during equilibration with the glucose 6-phosphate pool) and $\left[6-{ }^{3} \mathrm{H}\right]$ glucose (a tracer which retains its label during passage through the glucose 6-phosphate pool).

\section{Statistical analysis}

Data in text are expressed as mean \pm SEM. Fasting rates of turnover represent the mean of the three values determined from -30 to $0 \mathrm{~min}$. Integrated postprandial responses were calculated using the trapezoidal rule. The hypotheses that postprandial plasma glucose concentrations and rates of hepatic glucose release and cycling would be higher and initial splanchnic glucose clearance lower during the suppressed than during the constant glucagon study were tested using Student's one-tailed paired $t$-test. All other comparisons were two-tailed. A $p$ value of less than 0.05 was considered to be statistically significant.

\section{Results}

Plasma glucose, insulin and glucagon concentrations. Fasting plasma glucose concentrations were similar on both study days (Fig.1, upper panel). The constant glucagon infusion resulted in higher $(p<0.01)$ postprandial glucose concentrations $(120 \mathrm{~min}: 10.3 \pm$ 0.4 vs $8.1 \pm 0.7 \mathrm{mmol} / \mathrm{l})$ and a greater $(p<0.02)$ integrated postprandial glycaemic response $(3.3 \pm 0.3$ vs $2.9 \pm 0.2 \mathrm{mmol} / \mathrm{l}$ per $6 \mathrm{~h}$ ) than did the suppressed glucagon infusion.

Fasting peripheral glucagon concentrations averaged $77 \pm 4$ and $79 \pm 3 \mathrm{pg} / \mathrm{ml}$, respectively on the con-
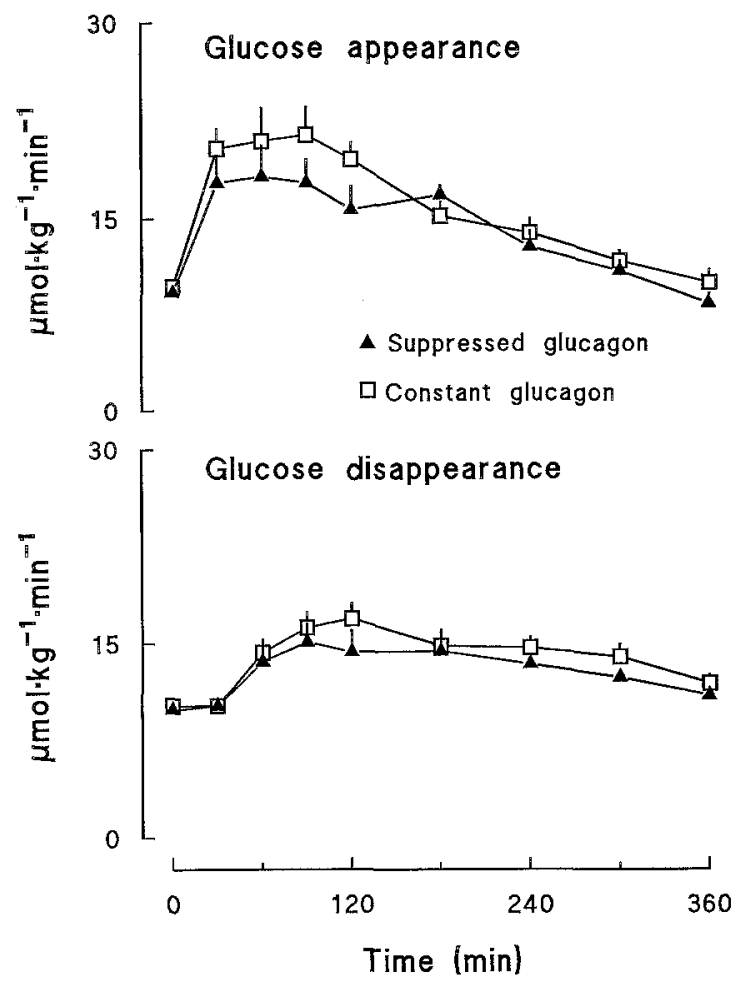

Fig. 2. Rates of glucose appearance and disappearance observed in the presence of either constant or suppressed glucagon. At time zero $50 \mathrm{~g}$ glucose was ingested

stant and suppressed glucagon study days (Fig. 1, middle panel). Following glucose ingestion, plasma glucagon decreased on the suppressed glucagon study day to levels averaging $63 \pm 1 \mathrm{pg} / \mathrm{ml}$ from 0 to $120 \mathrm{~min}$. Thereafter glucagon increased to $110 \pm 2$ $\mathrm{pg} / \mathrm{ml}$ which did not differ from that present throughout the postprandial period on the constant glucagon study day $(109 \pm 2 \mathrm{pg} / \mathrm{ml})$.

The basal insulin infusion rates required to maintain euglycaemia $(0.8 \pm 0.1$ vs $0.9 \pm 0.1 \mathrm{IU} / \mathrm{h}) \mathrm{did}$ not differ during the suppressed and constant glucagon studies. Plasma insulin concentrations also were equivalent both prior to and following glucose ingestion on both study days (Fig. 1, bottom panel). C-peptide and growth hormone concentrations remained comparably suppressed in both groups following glucose ingestion (data not shown). Fasting growth hormone concentrations were slightly higher on the constant than on the suppressed glucagon study day due to spontaneous pulses of growth hormone which occurred in four individuals prior to glucose ingestion.

Rates of glucose appearance and disappearance. The higher postprandial glucose concentrations observed on the constant glucagon study day were due to increased rates of glucose appearance rather than to decreased rates of disappearance (Fig. 2). Glucose appearance was greater $(p<0.05)$ on the constant than suppressed study days $(5.7 \pm 0.4$ vs $5.1 \pm$ $0.2 \mathrm{mmol} \cdot \mathrm{kg}^{-1}$ per $6 \mathrm{~h}$ ) with the differences being 


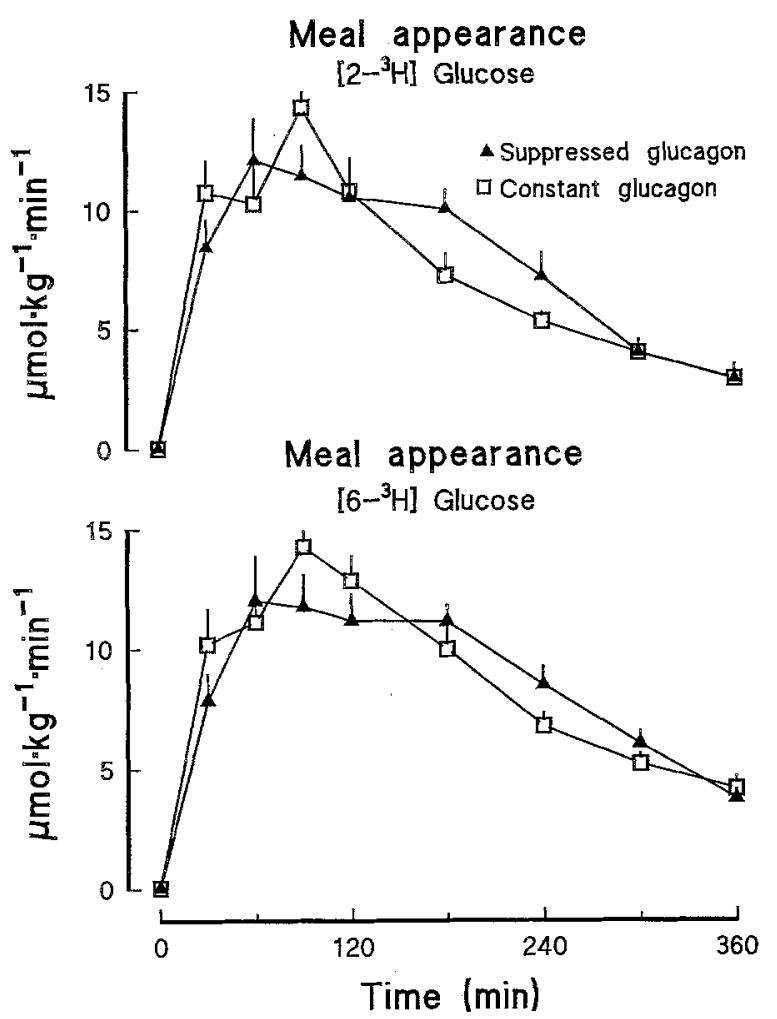

Fig.3. Rates of appearance of ingested glucose calculated using either the $\left[2-{ }^{3} \mathrm{H}\right]$ glucose or $\left[6^{3} \mathrm{H}\right]$ glucose contained in the meal as the tracer. At time zero $50 \mathrm{~g}$ glucose containing both $\left[2-{ }^{3} \mathrm{H}\right]$ glucose and $\left[6-{ }^{3} \mathrm{H}\right]$ glucose was ingested

most evident during the first $2 \mathrm{~h}$ after the meal. Glucose disappearance if anything was more rapid during the constant glucagon infusion presumably due to the mass action effect of the higher glucose concentrations.

Rates of appearance of ingested glucose, hepatic glucose release and hepatic glucose cycling. The higher postprandial glucose concentrations during the constant glucagon infusion could not be ascribed to decreased initial splanchnic glucose clearance since the systemic rate of appearance of the glucose contained in the meal did not differ on the two study days whether measured using the ingested $\left[2-{ }^{3} \mathrm{H}\right]$ glucose (Fig. 3, upper panel) or the ingested $\left[6-{ }^{3} \mathrm{H}\right]$ glucose (Fig. 3, lower panel). Plasma D-xylose concentrations (an index of glucose absorption) also did not differ on the two study days (data not shown). In contrast, postprandial hepatic glucose release was greater $(p<0.02)$ on the constant than suppressed glucagon study (Fig. 4) whether measured using $\left[2-{ }^{3} \mathrm{H}\right]$ glucose $(3.0 \pm 0.3$ vs $2.4 \pm 0.2 \mathrm{mmol} / \mathrm{kg}$ per $6 \mathrm{~h})$ or $\left[6{ }^{3} \mathrm{H}\right] \mathrm{glu}-$ cose $(2.6 \pm 0.2$ vs $2.0 \pm 0.2 \mathrm{mmol} / \mathrm{kg}$ per $6 \mathrm{~h})$. Postprandial hepatic glucose cycling tended to be slightly but not significantly higher during the constant than during the suppressed glucagon study (Fig. 5).
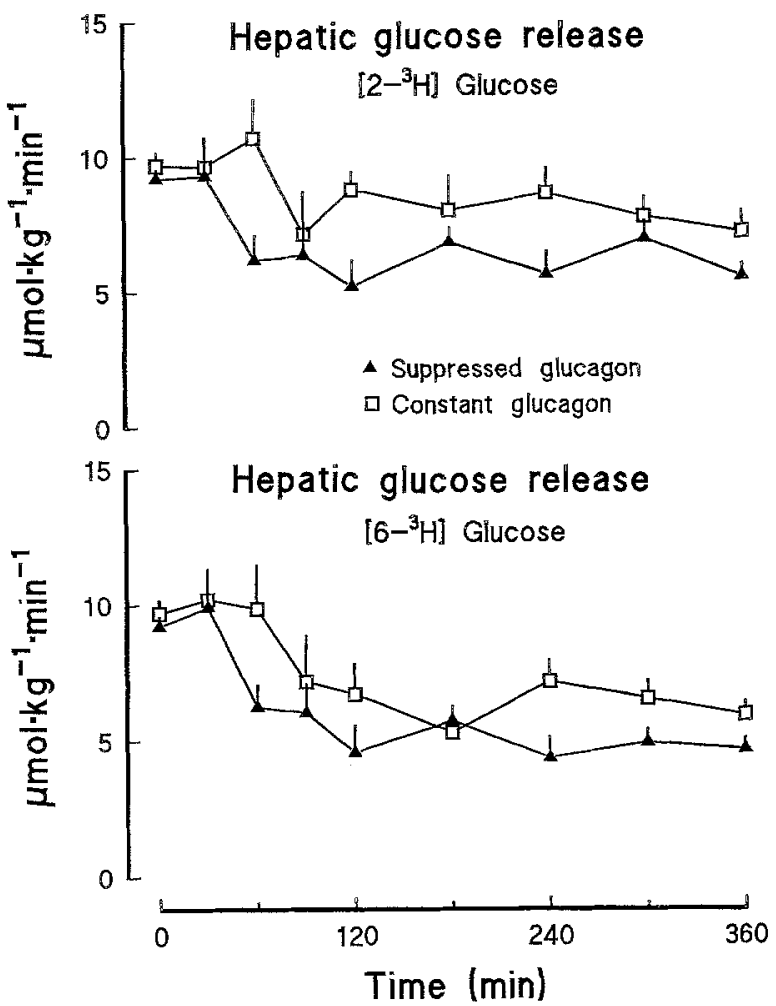

Fig.4. Hepatic glucose release is calculated by subtracting the rate of appearance of ingested glucose from total glucose appearance. Upper panel shows hepatic glucose release calculated by subtracting meal appearance traced with $\left[2-{ }^{3} \mathrm{H}\right]$ glucose from total glucose appearance. Lower panel shows hepatic glucose release calculated by subtracting meal appearance traced with $\left[6-{ }^{3} \mathrm{H}\right] \mathrm{glucose}$ from total glucose appearance. At time zero $50 \mathrm{~g}$ glucose containing both $\left[2-{ }^{3} \mathrm{H}\right]$ glucose and [6$\left.{ }^{3} \mathrm{H}\right]$ glucose was ingested

\section{Discussion}

In the absence of either hypoglycaemia or stress, changes in glucagon concentrations primarily occur in response to food ingestion [1,2,12-14]. In non-diabetic individuals glucagon concentrations fall as glucose concentrations rise, and rise as glucose concentrations return toward preprandial levels [12-14]. This reciprocal relationship between glucose and glucagon is abolished by diabetes mellitus $[1,2,11]$. Glucagon concentrations not only tend to be elevated in the postabsorptive state but, perhaps more importantly, are not suppressed following carbohydrate ingestion. The present experiments demonstrate that this failure to suppress glucagon results in a substantial deterioration in glucose tolerance due to excessive postprandial hepatic glucose release. The inappropriately elevated postprandial glucagon concentrations had no effect on initial splanchnic glucose clearance, hepatic glucose cycling or rates of glucose disappearance.

The role of glucagon in the day-to-day regulation of glucose homeostasis has been difficult to define. 


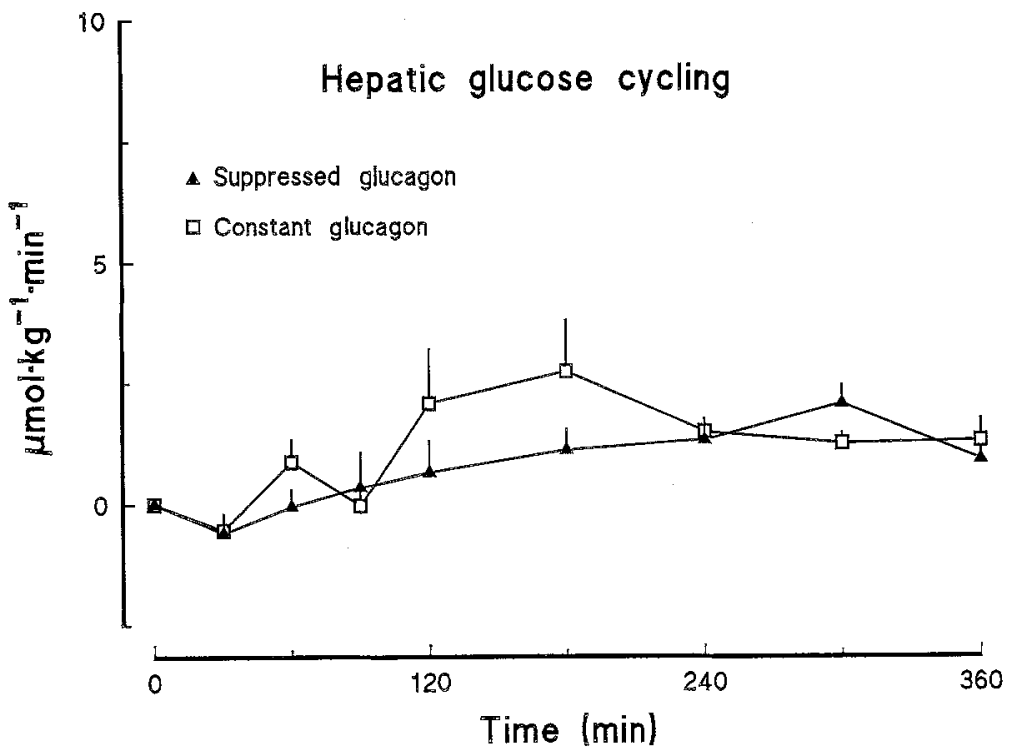

Fig.5. Hepatic glucose cycling was calculated by subtracting meal appearance traced with $\left[6-{ }^{-3} \mathrm{H}\right]$ glucose from that traced with $\left[2{ }^{3} \mathrm{H}\right]$ glucose. At time zero $50 \mathrm{~g}$ glucose containing both $\left[2-{ }^{3} \mathrm{H}\right]$ glucose and $\left[6-{ }^{3} \mathrm{H}\right] \mathrm{glucose}$ was ingested
The difficulty arises mainly from the fact that glucagon is an insulin secretagogue and insulin is an inhibitor of glucagon secretion $[1,2]$. Therefore, physiologic changes in glucagon seldom occur without associated changes in circulating insulin concentrations. Any effects of glucagon on carbohydrate metabolism could potentially be offset by insulin, secreted in response to the increase in glucagon or the increase in glucose. In a review of this subject in 1978, Unger stated: "...studies of the actions of exogenous glucagon on fuel homeostasis can be regarded as valid only if compensatory insulin secretion has been effectively blocked. .." [1]. Changes in portal venous insulin concentrations likely account for previous failures to detect an effect of glucagon on postprandial carbohydrate tolerance in non-diabetic volunteers [7-9]. In the present experiment we studied C-peptide deficient individuals, thereby enabling us to control for insulin as a potential confounding variable. We have used a similar approach in the past to establish that episodic increases in glucagon concentrations can cause sustained hyperglycaemia [21]. In those experiments as in the present experiments, glucose concentrations eventually fell back toward baseline; however, each increase in glucagon led to a concomitant increase in glucose. Presumably the same phenomenon occurs in people with IDDM under the conditions of daily living. The failure to suppress glucagon leads to progressively higher glucose concentrations prior to the next meal. This combined with the excessive postprandial rise in glucose results in an increase in the integrated glucose concentration to which peripheral tissues are exposed.

Our finding of higher rates of hepatic glucose release when a postprandial fall in glucagon is prevented is consistent with the known biologic effects of glucagon [3-6]. The accelerated rates of glucose release are particularly notable since they occurred in the presence of a known inhibitor of glucose production (i.e. higher glucose concentrations). Previous studies have shown that stimulation of glycogenolysis by glucagon appears to be transient since hepatic glucose release returns toward baseline despite continued hyperglucagonaemia [22-24]. However, a persistent glucagon effect is evinced by a rise or fall in glucose release when plasma glucagon concentration is either increased or decreased $[25,26]$. Therefore, a change in plasma glucagon concentration, or more precisely, a change in the portal insulin/glucagon ratio appears to be the major regulator of hepatic glucose release. Thus, the normal or slightly elevated postabsorptive glucagon concentrations in people with IDDM can exert a sustained stimulatory effect on hepatic glucose release.

The somatostatin-induced decrease in glucagon concentrations in the diabetic patients following food ingestion was accompanied by a lower rate of hepatic glucose release. Although we failed to detect differences in initial splanchnic glucose extraction on the two days, this does not exclude an effect of glucagon on hepatic glycogen synthesis. Glucagon is a well-known antagonist of insulin-induced stimulation of glycogen synthetase [6]. In the current experiments, inhibition may have been masked by a stimulatory effect of the higher glucose concentrations that occurred when glucagon was not suppressed. This issue potentially can be addressed in future studies by clamping postprandial glucose concentrations at the same levels in the presence and absence of suppression of glucagon.

Hepatic glucose cycling refers to the concomitant uptake and release of glucose by the liver [27]. Cycling generally has been calculated by comparing rates of turnover measured with $\left[2-{ }^{3} \mathrm{H}\right]$ glucose to those obtained with $\left[6{ }^{3} \mathrm{H}\right]$ glucose since the former is detritiated during passage through the glucose 6phosphate pool whereas the latter is not [27]. As dis- 
Table 1. Changes in glucagon concentration on two study days

\begin{tabular}{|c|c|c|c|c|}
\hline \multirow[t]{2}{*}{ Glucagon } & \multicolumn{2}{|l|}{$\begin{array}{l}\text { Peripheral } \\
(\mathrm{pg} / \mathrm{ml})\end{array}$} & \multicolumn{2}{|l|}{$\begin{array}{l}\text { Portal } \\
(\mathrm{pg} / \mathrm{ml})\end{array}$} \\
\hline & Preprandial & Postprandial & Preprandial & Postprandial \\
\hline $\begin{array}{l}\text { Constant } \\
\text { Suppressed }\end{array}$ & $\begin{array}{l}\sim 80 \\
\sim 80\end{array}$ & $\begin{array}{r}\sim 110 \\
\sim 60\end{array}$ & $\begin{array}{l}\sim 160 \\
\sim 160\end{array}$ & $\begin{array}{l}\sim 170 \\
\sim 120\end{array}$ \\
\hline
\end{tabular}

Postprandial $=0-120 \mathrm{~min}$ following glucose ingestion

cussed in detail elsewhere, this approach provides a reasonable but not perfect estimate of cycling [28]. Cycling can result from simultaneous formation and degradation of glycogen and/or concurrent activation of glucokinase and glucose 6-phosphatase. Several investigators have reported that acute increases in plasma glucagon to $\sim 300-400 \mathrm{pg} / \mathrm{ml}$ increases glucose cycling $[4,5]$. Increased cycling also has been observed in subjects with non-insulin-dependent diabetes during intravenous glucose infusion or following food ingestion [13, 29]. In the latter study [13],we noted a modest increase in cycling that was positively correlated with the plasma glucagon concentration present during the $2 \mathrm{~h}$ following food ingestion. We speculated that the failure to suppress glucagon (which was also observed in those individuals) caused the increased glucose cycling. Results from the current experiment argue against this hypothesis. Hepatic glucose cycling was minimally but not significantly higher in the absence than in the presence of a postprandial fall in glucagon concentrations. Thus, while an acute elevation in glucagon concentrations, such as occur with hypoglycaemia, may increase hepatic glucose cycling, cycling is unlikely to be influenced by changes in glucagon concentration of a magnitude that occur under the conditions of daily living.

As with all studies, the current experiment has limitations. The major one relates to our inability to measure portal glucagon concentrations. In the few studies in which portal glucagon concentrations have been measured in humans, the data indicate a $50 \%$ extraction of glucagon by the liver $[30,31]$. We can assume therefore that since our prandial peripheral glucagon concentration was $\sim 80 \mathrm{pg} / \mathrm{ml}$, the concomitant portal concentration was $\sim 160 \mathrm{pg} / \mathrm{ml}$. On the suppressed glucagon study day peripheral glucagon concentrations declined to a mean of $\sim 60 \mathrm{pg} / \mathrm{ml}$, i.e. a $20 \mathrm{pg} / \mathrm{ml}$ decrement from prandial levels. Since somatostatin inhibits the secretion of the 3500 molecular weight species of glucagon [32] its effect is seen first in the portal circulation, implying that the decrement in postprandial portal glucagon concentration must be $\sim 40 \mathrm{pg} / \mathrm{ml}$. Therefore, the portal glucagon concentration on the suppressed study day was $\sim 120$ $\mathrm{pg} / \mathrm{ml}$. On the constant glucagon study day the postprandial peripheral glucagon concentration averaged $\sim 110 \mathrm{pg} / \mathrm{ml}$. This $\sim 110 \mathrm{pg} / \mathrm{ml}$ represents the sum of $60 \mathrm{pg} / \mathrm{ml}$ that would have occurred in the absence of the glucagon infusion plus $50 \mathrm{pg} / \mathrm{ml}$ coming from the glucagon infusion. Using the same logic, the portal glucagon concentration during the constant infusion represented the sum of $\sim 120 \mathrm{pg} / \mathrm{ml}$ that would have occurred in the absence of the glucagon infusion plus the additional $50 \mathrm{pg} / \mathrm{ml}$ from the infusion. As shown in Table 1, this results in an increase in estimated portal glucagon concentrations of $\sim 10$ $\mathrm{pg} / \mathrm{ml}$. Therefore, while portal glucagon concentrations were not truly maintained at "basal" levels, the slight increase is of a magnitude equal to or less than the paradoxical increase that is frequently observed following food ingestion in IDDM subjects whose glycaemic control is suboptimal $[1,2,10]$. On the other hand, glucagon was given as a constant rather than as a pulsatile infusion. To the extent that pulsatile glucagon administration has a greater biologic effect than constant [33] we may have underestimated the difference in glycaemia that would have been observed in the presence and absence of postprandial suppression of glucagon.

Somatostatin was used to suppress glucagon. Somatostatin has a variety of effects other than inhibition of alpha-cell secretion. It was for this reason that the same dose of somatostatin was infused on both study days. High doses of somatostatin decrease gastric motility and impair nutrient absorption [34]. Consistent with previous reports [34], we established in pilot studies that the dose of somatostatin can be titrated so that when infused in small amounts (i.e. $7 \mathrm{ng} / \mathrm{kg}$ per $\mathrm{min}$ ) it has minimal or no effect on carbohydrate absorption while still inhibiting pancreatic hormone secretion. As an added precaution $\mathrm{D}$-xylose was included in the test meal. The equivalent D-xylose concentration curves strongly suggest that absorption was comparable on both study days.

In conclusion, the present studies demonstrate that failure to suppress glucagon following glucose ingestion exacerbates postprandial hyperglycaemia in IDDM subjects. This deterioration in carbohydrate tolerance is due to increased rates of hepatic glucose release. Lack of suppression of glucagon does not substantially alter glucose cycling or initial splanchnic glucose uptake. These data indicate that therapy for IDDM subjects is unlikely to result in completely normal carbohydrate tolerance unless both the concentration and pattern of change of glucagon following glucose ingestion is also restored to normal. 
Acknowledgements. We wish to thank E. Butkiewicz, J. King, T. Madson, and D. Nash for their technical assistance, Ms. A. Pelot for assistance in preparation of the manuscript and the staff of the Mayo General Clinical Research Center for their assistance in performing the studies. This work was supported by U.S.P.H.S. (DK29953, RR00585) and the Mayo Foundation. Dr. A. Alzaid was supported by a mentor-based American Diabetes Association Research Fellowship Award and by the Armed Forces Hospital, Riyadh, Saudi Arabia.

\section{References}

1. Unger RH (1978) Role of glucagon in the pathogenesis of diabetes: the status of the controversy. Metabolism 27:1691-1709

2. Lefebvre PJ, Luyckx AS (1979) Glucagon and diabetes: a reappraisal. Diabetologia 16:347-354

3. Stevenson RW, Steiner KE, Davis MA et al. (1987) Similar dose responsiveness of hepatic glycogenolysis and gluconeogenesis to glucagon in vivo. Diabetes 36:382-389

4. Lickley HLA, Kemmer FW, El-Tayeb KMA, Vranic M (1987) Importance of glucagon in the control of futile cycling as studied in alloxan-diabetic dogs. Diabetologia 30:175-182

5. Miyoshi H, Shulman GI, Peters EJ, Wolfe MH, Elahi D, Wolfe RR (1988) Hormonal control of substrate cycling in humans. J Clin Invest 81:1545-1555

6. Hers HG (1976) The control of glycogen metabolism in the liver. Annu Rev Biochem 45:167-187

7. Liljenquist JE, Rabin D (1979) Lack of a role for glucagon in the disposal of an oral glucose load in normal man. $J$ Clin Endocrinol Metab 49:937-939

8. Holst JJ, Madsen OG, Knop J, Schmidt A (1977) The effect of intraportal and peripheral infusions of glucagon on insulin and glucose concentrations and glucose tolerance in normal man. Diabetologia 13:487-490

9. Sherwin RS, Fisher M, Hendler R, Felig P (1976) Hyperglucagonemia and blood glucose regulation in normal, obese and diabetic subjects. N Engl J Med 294:455-461

10. Raskin P, Unger RH (1978) Effect of insulin therapy on the profiles of plasma immunoreactive glucagon in juveniletype and adult-type diabetes. Diabetes 27:411-419

11. Gerich JE, Tsalikian E, Lorenzi M et al. (1975) Normalization of fasting hyperglucagonemia and excessive glucagon responses to intravenous arginine in human diabetes mellitus by prolonged infusion of insulin. J Clin Endocrinol Metab 41:1178-1180

12. Tse TF, Clutter WE, Shah SD, Miller JP, Cryer PE (1983) Specificity, temporal relationships, and quantitative aspects. J Clin Invest 72:270-277

13. Butler RC, Rizza RA (1991) Contribution to postprandial hyperglycemia and effect on initial splanchnic glucose clearance of hepatic glucose cycling in glucose-intolerant or NIDDM patients. Diabetes 40:73-81

14. Dinneen S, Alzaid A, Miles J, Rizza R (1993) Metabolic effects of the nocturnal rise in cortisol on carbohydrate metabolism in normal humans. J Clin Invest 92:2283-2290

15. White NH, Skor D, Santiago JV (1982) Practical closedloop insulin delivery. A system for the maintenance of overnight euglycemia and the calculation of basal insulin requirements in insulin-dependent diabetics. Ann Intern Med 97:210-213

16. Firth RG, Bell PM, Marsh HM, Hansen I, Rizza RA (1986) Postprandial hyperglycemia in patients with noninsulin-dependent diabetes mellitus. J Clin Invest 77:1525-1532
17. Katz H, Homan M, Jensen M, Caumo A, Cobelli C, Rizza $R$ (1994) Assessment of insulin action in NIDDM in the presence of dynamic changes in insulin and glucose concentration. Diabetes 43:289-296

18. Eberts TJ, Sample RH, Glick MR, Ellis GH (1979) A simplified, colorimetric micromethod for xylose in serum or urine with phloroglucinol. Clin Chem 25:1440-1443

19. Bell PM, Firth RG, Rizza RA (1986) Assessment of insulin action in insulin-dependent diabetes mellitus using [6$\left.{ }^{14} \mathrm{C}\right]$ glucose, $\left[3-{ }^{3} \mathrm{H}\right]$ glucose, and $\left[2-{ }^{3} \mathrm{H}\right]$ glucose. Differences in the apparent pattern of insulin resistance depending on the isotope used. J Clin Invest 78:1479-1486

20. Steele R, Wall JS, De Bodo RC, Altszuler N, Kiang SP, Bjerknes C (1956) Measurement of size and turnover rate of body glucose pool by the isotope dilution method. Am J Physiol 187:15-24

21. Rizza R, Verdonk C, Miles J, Service J, Gerich J (1979) Effect of intermittent endogenous hyperglucagonemia on glucose homeostasis in normal and diabetic man. J Clin Invest 63:1119-1123

22. Bomboy JD Jr, Lewis SB, Lacy WW, Sinclair-Smith BC, Liljenquist JE (1977) Transient stimulatory effect of sustained hyperglucagonemia on splanchnic glucose production in normal and diabetic man. Diabetes 26:177-184

23. El-Refai M, Bergman RN (1979) Glucagon-stimulated glycogenolysis: time-dependent sensitivity to insulin. Am J Physiol 236:E246-E254

24. Cherrington AD, Diamond MP, Green DR, Williams PE (1982) Evidence for an intrahepatic contribution to the waning effect of glucagon on glucose production in the conscious dog. Diabetes 31:917-922

25. Rizza RA, Gerich JE (1979) Persistent effect of sustained hyperglucagonemia on glucose production in man. $\mathrm{J}$ Clin Endocrinol Metab 48:352-355

26. Fradkin J, Shamoon H, Felig P, Sherwin RS (1980) Evidence for an important role of changes in, rather than absolute concentrations of, glucagon in the regulation of glucose production in humans. J Clin Endocrinol Metab 50:698-703

27. Katz J, Rognstad R (1976) Futile cycles in the metabolism of glucose. In: Horecker BL, Stadtman ER (eds) Current topics in cellular regulation, Academic Press, New York, pp. 237-289

28. Wajngot A, Chandramouli V, Schumann WC, Kumaran K, Efendic S, Landau BR (1989) Testing of the assumptions made in estimating the extent of futile cycling. Am J Physiol 256:E668-E675

29. Efendic S, Wajngot A, Vranic M (1985) Increased activity of the glucose cycle in the liver: early characteristic of type 2 diabetes. Proc Natl Acad Sci USA 82:2965-2969

30. Jaspan JB, Ruddick J, Rayfield E (1984) Transhepatic glucagon gradients in man: evidence for glucagon extraction by human liver. J Clin Endocrinol Metab 58:287-292

31. Blackard WG, Nelson NC, Andrews SS (1974) Portal and peripheral vein immunoreactive glucagon concentrations after arginine or glucose infusions. Diabetes 23:199-202

32. Jaspan JB, Polonsky KS, Lewis M et al. (1981) Hepatic metabolism of glucagon in the dog: contribution of the liver to overall metabolic disposal of glucagon. Am J Physiol 240:E233-E244

33. Paolisso G, Scheen AJ, Albert A, Lefebvre PJ (1989) Effects of pulsatile delivery of insulin and glucagon in humans. Am J Physiol 257:E686-E696

34. Johansson C, Wisen O, Efendic S, Uvnuäs-Wallensten K (1981) Effects of somatostatin on gastrointestinal propagation and absorption of oral glucose in man. Digestion 22:126-137 